\title{
EFEKTIFITAS PERMAINAN TRADISIONALTERHADAP PERKEMBANGAN MOTORIK ANAK USIA PRASEKOLAH
}

\author{
Andi Akifa Sudirman ${ }^{1}$, Dewi Modjo ${ }^{2}$, Firmawati $^{3}$, Ummu Kalsum $^{4}$ \\ Universitas Muhammadiyah Gorontalo ${ }^{1,2,3,4}$ \\ Email : andiakifasudirman@umgo.ac.id.
}

\begin{abstract}
Motoric development is a process of children to learn skilled in moving the limbs. One of the stimulation in motoric development that is with the Games. This research was conducted at TK AisyiyahBustanulAtfal I of Gorontalo City. The purpose of this study was to identify the effect before and after the traditional games given to motoric development of preschoolers. The study design used pre-experimental one group pretest-postest. Population: all of students aged 4 until 5 years at TK Aisyiyah Bustanul Atfal I of Gorontalo City as many as 65 students. The sample of the study amounted to 18 respondents. Traditional games were done 16 times in 5 weeks, motoric development assessment before and after treatment using Dependent $T$ test on significance level of $95 \%(\alpha=0,05)$. The results of the study is the motoric has differences after and before the traditional game, with $p$ value $0.000<\alpha-0,05$. Conclusion: There is an influence of traditional games on children motoric development of preschoolers. Suggestions: relevant agencies to contribute thoughts and implementation of traditional games are strained at least once a week.
\end{abstract}

Keywords: Motoric, Development, Traditional Games

\section{PENDAHULUAN}

Perkembangan anak dibawah lima tahun (Balita) merupakan bagian yang sangat penting (Kemenkes RI, 2013). Pada masa ini anak mengalami periode kritis, berbagai bentuk penyakit, kekurangan gizi, serta kekurangan kasih sayang maupun kekurangan stimulasi pada usia ini akan membawa dampak negatif yang menetap sampai masa dewasa bahkan sampai usia lanjut (Depkes, 2014). Stimulasi hendaknya diberikan sejak dini dan sesuai perkembangan anak yang meliputi kemampuan gerak kasar dan gerak halus, kemampuan bicara dan bahasa, serta kemampuan sosialisasi dan kemandirian (Depkes, 2012).

Perkembangan teknologi yang semakin lama bertambah canggih, banyak orang yang dimanjakan oleh teknologi modern seperti televisi, handphone, playstation dan smartphone. Kesan dari perkembangan teknologi moderen tidak selamanya berdampak positif bagi dunia anak-anak.Fenomena yang terjadi akhirakhir ini, banyak permainan digital yang berdampak negatif bagi anak. Hal tersebut akan menyebabkan aktivitas anak akan semakin berkurang karena anak-anak sibuk 
dengan gadget, sehingga menimbulkan perkembangan motorik menjadi terhambat (Perwitasari, 2016).

Perbedaan besar antara permainan masa kini dengan permainan tradisional adalah pada zaman dahulu permainan trasional tidak cuma melatih otak, perasaan, emosional seseorang, tetapi juga melatih keseimbangan gerak dan ketangkasan tubuh, hal ini sangat jauh berbeda dengan permainan modern. Permainan tradisional merupakan permaian yang dapat digunakan untuk membantu anak dalam perkembangan motorik. Keuntungan permainan tradisional dapat menambah kreativitas anak dalam mengelola permainan dan mengembangkan kemampuan interaksi sesama anak, karena pada dasarnya permainan tradisional cenderung pada permainan kelompok yang menumbuhkan kerja sama yang baik (Muliawan, 2009).

Anak menghabiskan waktu selama 4 jam di sekolah dan ditemani oleh guru tanpa orang tua, salah satu stimulasi perkembangan yang diberikan oleh guru adalah belajar danbermain disekolah merupakan role model lanjutan dirumah. Melalui media permainan yang baik anak dapat mengeskpresikan perasaan serta daya kreasi yang dapat mengembangkan kreativitasnya dan beradaptasi lebih efektif terhadap berbagai sumber stress. Dalam hal ini orang tua hendaknya memperhatikan alat permainan yang digunakan oleh anak apakah aman dan harus disesuaikan dengan perkembangan usia anak agar permainan tersebut dapat memberikan fungsi dengan benar dan mempunyai unsur edukatif bagi anak untuk perkembangan motorik halus maupun motorik kasar.

Berdasarkan pengambilan data awal peneliti lakukan pada tanggal 4 Desember 2017 bahwa siswa di TK Aisyiyah Bustanul Atfal I Kota Gorontalodengan dengan anak yang berumur 4 tahun sebanyak 13 laki-laki dan 4 perempuan, anak berumur 5 tahun laki-laki sebanyak 28 anak dan 20 anak perempuan, sedangkan anak yang berumur 6 tahun hanya 1 laki-laki saja, sertapermainan untuk mengasah kemampuan motorik anak masih menggunakan metode permainan seperti balok, ayunan, dan perosotan. Adapun wawancara dengan salah seorang guru di TK Aisyiyah Bustanul Atfal I Kota Gorontalo mengatakan bahwa perkembangan motorikanak belum berkembang dengan baik. Ini dibuktikan pada observasi awal yang dilakukan oleh peneliti pada beberapa anak belum mampu melompat-lompat 1 kaki, berhitung, serta meniru sebuah lingkaran. Pada permainan tradisional seperti tengge-tengge ini dapat melatih kemampuan motorik kasar anak yaitu melakukan gerakan melompat dan berlari secara terkoordinasi,serta mampu melatih kemampuan motorik halus anak yaitu memegang dan berhitung.

Permainan tradisional ialah aktivitas budaya dalam bentuk permainan dengan unsur-unsur gerak, seni, sosial, dan budaya. Sebagai aktivitas budaya, permainan itu mengandung sumber dan media informasi yang dapat mewarnai dan dapat memperkaya kebudayaan nasional maupun daerah, serta memperkukuh nilai-nilai budaya yang dapat merangsang kearah pembaharuan yang kreatif (Nopilayanti, 
Wiyasa, dan Negara, 2016). Permainan tradisional adalah permainan yang memiliki unsur-unsur budaya yang tubuh dan berkembang dalam masyarakat sesuai dengan aturan dan norma adat kebiasaan yang diwarisi dan dipelihara secara turun temurun baik menggunakan alat atau tanpa alat dalam permainannya (Rahmadani, 2014).

Permainan Tradisional Gorontalo

a. Tengge-tengge / Engklek

Permainan tengge-tengge (dalam bahasa Gorontalo) merupakan permainan tradisional lompat-lompatan pada bidang-bidang datar yang digambar di atas tanah, dengan membuat gambar kotak-kotak kemudian melompat dengan satu kaki dari kotak satu ke kotak berikutnya. Permainan tengge-tengge bisa dimainkan oleh 2-5 anak perempuan dan dilakukan di halaman. Namun sebelum memulai permainan kita harus membuat kotak-kotak besar di pelataran semen, aspal atau tanah, menggambar 5 segi empat berhimpit vertical kemudian di sebelah kanan dan kiri diberi lagi sebuah segi empat (Ardini. 2013).

Permainan ini dapat mengasah kemampuan motorik kasar dan motorik halus anak. Untuk kemampuan motorik kasar anak yaitu berdiri dengan satu kaki selama 6 sampai 8 detik tanpa berpegangan dan jatuh. Serta kemampuan motorik halus yaitu dengan memegang benda tersebut sambil berlompat dengan satu kaki.

b. Awuta/Congklak

Awuta adalah permainan tradisional di Gorontalo yang masih sering kita jumpai. Permainan ini sangat baik untuk mengasah kemampuan motorik halus dan kemampuan kognitif anak. Untuk kemampuan motorik halus yaitu anak belajar memindahkan benda dari tangannya dan memegang suatu benda tanpa jatuh. Sedangkan kemampuan kognitif anak diasah dengan cara menghitung dengan konsentrasi yang baik.

c. Bilu-Bilulu / Hadang

Bilu-bilulu, adalah nama burung kecil yang gesit, konon berasal dari nama seorang anak laki-laki yang sedang memburu burung tersebut.

Permaian ini sering di mainkan oleh anak berUsia 6-12 tahun. Pada permainan ini kita dituntut untuk konsentrasi dalam ketangkasan berlari dan mengambil kesempatan. Permainan ini mengasah kemampuan motorik kasar dan sosial emosional.

d. Cur-Pal

Cur-pal adalah permainan yang dilakukan di lapangan atau di halaman yang luas yang dimainkan oleh 3 sampai 5 orang. Cur-pal merupakan permainan yang mengasah kemampuan motorik kasar anak yaitu kemampuan dengan berlari.

e. Ular Tangga

Permainan ular tangga adalah permainan yang dikenal di seluruh nusantara. Ular tangga dapat dimainkan sendiri. Tetapi tentunya tidak asik seperti saat dimainkan oleh lebih dari dua orang. Permainan ular tangga menggunakan 3 
peralatan yaitu dadu, bidang, dan papan ular tangga. Dadu berfungsi sebagai penentu langkah setiap bidak.

Pada permainan ini dapat mengasah kemampuan motorik halus dan kemampuan kognitif anak dimana anak belajar memindahkan benda disetiap kotak dan sambil berhitung.

f. Lompat Tali

Permainan lompat tali dimainkan perorangan atau berkelompok. Lompat tali yang dimainkan perorangan dilakukan dengan cara skiping, yaitu memegang kedua ujung tali kemudian mengayunkannya melewati kepala dan kaki sambil melompatinya.

Lompat tali dapat mengasah kemampuan motorik kasar anak yaitu melompat dengan satu kaki. Disamping itu pada permainan ini dapat mengasah kemampuan sosial anak belajar bekerja sama antar teman.

g. Tumbu-tumbu balanga

Permainan menggunakan semacam syair/mantera, semula bertujuan untuk membujuk bayi yang menangis, dilakukan dengan menepuk-nepuk meja atau kursi dengan kepalan tangan, pukulan yang kian keras, terbukti mampu mencuri perhatian bayi yang menanggis hingga terdiam.

Permainan ini adalah permainan yang mampu mengasah kemampuan motorik halus anak dan dapat mengembangkan kemampuan sosial emosional anak. Dimana anak belajar membuka dan mengepalkan tangannya dan menyusunnya menjadi seperti sebuah menara, disamping itu anak juga belajar untuk bersabar dengan iring-iringan lagu menunggu giliran tangan untuk dibuka.

Tujuan penelitian ini adalah diketahuinya efektifitas permainan tradisional terhadap perkembangan motorik anak usia pra sekolah di TK Aisyiyah Bustanul Atfal I

\section{METODOLOGI PENELITIAN}

Pada penelitian ini, yang penulis gunakan adalah penelitian kuantitatif dengan jenis penelitian eksperimen. Desain penelitian yang digunakan adalah one group Pretest-Posttest.

Variabel bebas dalam penelitian ini adalah Permainan Tradisional sedangkan variabel terikat dalam penelitian ini adalah Perkembangan Motorik Anak

Populasi penelitian dalam penelitian ini merupakan siswa di TK Aisyiyah Bustanul Atfal I Kota Gorontalo berjumlah 65 anak. Sampel dalam penelitian ini sebanyak 18 anak dengan usia 4 tahun 6 anak dan 5 tahun 12 anak.

Teknik pengumpulan data dalam penelitian ini terdiri atas dua yaitu primer dan sekunder. analisa data dilakukan dengan sitem komputer yang terdiri dari analisis univariat dan analisis bivariat menggunakan uji statistik T-test Dependen (Paired Sample T-test) dengan tingkat kemaknaan 95\% $(\alpha=0,05)$. 


\section{HASIL DAN PEMBAHASAN}

Tabel 1. Karakteristik responden berdasarkan Usia, Jenis Kelamin, dan Pendidikan Orang Tua

\begin{tabular}{lcc}
\hline Karakteristik & n & \% \\
\hline Usia & 6 & 33,3 \\
4 tahun & 12 & 66,7 \\
5 tahun & & \\
Jenis Kelamin & 12 & 66,7 \\
Laki-laki & 6 & 33,3 \\
Perempuan & & \\
Pendidikan orang Tua & 9 & 50 \\
SMA & 7 & 38,9 \\
S1 & 2 & 11,1 \\
S2
\end{tabular}

Sumber : Data Primer dan Sekunder (2018)

Distribusi responden berdasarkan Usia 4 tahun sebanyak 6 anak $(33,3 \%)$, sedangkan Usia 5 tahun sebanyak 12 anak (66,7\%). Distribusi responden berdasarkan jenis kelamin laki-laki sebanyak 12 anak (66,7\%), sedangkan perempuan sebanyak 6 anak $(33,3 \%)$. Distribusi tingkat pendidikan orang tua yang terbanyak adalah SMA sebanyak 9 responden (50\%), sedangkan pendidikan orang tua yang paling sedikit yaitu S2 sebanyak 2 responden $(11,1 \%)$.

Tabel 2. Distribusi Nilai rata-rata Perkembangan Motorik Anak Sebelum dan Sesudah Permainan Tradisional

\begin{tabular}{lcc}
\hline Perkembangan Motorik & Mean & $\begin{array}{c}\text { Standar Deviasi } \\
(\mathrm{SD})\end{array}$ \\
\hline Sebelum & 16,17 & 2,407 \\
Sesudah & 17,72 & 1,841 \\
\hline
\end{tabular}

Sumber : Data Primer (2018)

Berdasarkan tabel diatas nilai rata-rata total skor pada perkembangan motorik anak sebelum dilakukan permainan tradisional adalah 16,17 dari 18 responden, dengan standar deviasi 2,407. Sedangkan sesudah diberikan permainan tradisional nilai rata-rata total skor pada perkembangan motorik anak adalah 17,72 dengan standar deviasi 1,841 . 
Tabel 3. Hasil Pengaruh Permainan Tradisional Terhadap Perkembangan Motorik Anak

\begin{tabular}{llll}
\hline \multicolumn{1}{c}{ Variabel } & Mean & SD & $\rho$ Value \\
\hline Perkembangan Motorik & & & \\
Sebelum & & & \\
Sesudah & 16,17 & 2,407 & 0,000 \\
\hline
\end{tabular}

Sumber : Data Primer 2018

Dari hasil uji statistik pada perkembangan motorik anak di dapatkan nilai 0,000 dan terlihat nilai perbedaan rata-rata adalah -1,556 dari rata-rata sebelum dan sesudah diberikan permainan tradisional dengan standar deviasi 1,097 dari sebelum dan sesudah di berikan permainan tradisional. Sehingga dapat di simpulkan terdapat pengaruh bermakna dan signifikan permainan tradisional terhadap perkembangan motorik anak.

Dalam penelitian ini akan membahas tentang efektifitas permainan tradisional terhadap perkembangan motorik anak usia pra sekolah di TK Aisyiyah Bustanul Atfal I. Salah satu permainan tradisional Gorontalo yang diberikan pada anak-anak yaitu permainan tengge-tengge atau engkelek.

Pemberian terapi bermain tradisional kepada sampel eksperimen selama 16 kali pertemuan (seminggu 3 kali bermain hari senin, selasa, dan rabu) dengan durasi 2 sampai 3 jam dan di damping oleh wali kelas. Hal ini sesuai yang dikemukakan Tjaliek Sugiardo (1991:4), bahwa proses latihan selama 16 kali sudah dapat dikatakan terlatih, sebab sudah ada perubahan yang menetap. Hasil penelitian ini sejalan dengan Leli Prastiwi 2016 tentang perbedaan sebelum dan sesudah terapi bermain permainan tradisional pada anak, dimana dalam penelitian tersebut melakukan dengan cara pemberian permainan tradisional kepada anak sebanyak 16 kali (1 minggu 3 kali pertemuan) dengan hasil kesimpulan dari penelitian yaitu terdapat perbedaan kemampuam motorik kasar sebelum dan sesudah diberi perlakukan.

Dari observasi peneliti bahwa permianan tengge-tengge dapat mengembangkan kemampuan motorik anak. Dimana anak harus melompat-lompat melewati kotak yang sudah dibuat sebelumnya dan anak memegang gacuk sampai akhir permainan. Oleh Karennya otot tangan dan otot kaki harus kuat. Permainan tradisional ini juga selain mengembangkan kemampuan motorik dapat juga mengembangkan kognitif anak dimana anak menghitung langkah dalam permainan.

Permainan tengge-tengge juga dapat mengembangkan kemampuan motorik kasar anak yaitu pada saat berdiri menggunakan satu kaki dapat melatih keseimbangan anak, melompati kotak-kotak yang terdapat dalam permainan 
dengan menggunakan satu kaki dan dua kaki, melempar gacuk ke kotak yang ditentukan dan membungkukkan badan saat mengambil gacuk, kemampuan motorik halus yang dapat di kembangkan yaitu dimana anak menangkap dan memegang gacuk sampai permainan selesai.

Pada prinsipnya bermain mempunyai tujuan, menurut Wulandari dan Erawati (2016) salah satu dari tujuan bermain yaitu untuk melanjutkan pertumbuhan dan perkembangan yang normal. Semua anak mempunyai ruang bermain untuk mengembangkan kreativitas sehingga hal ini akan mempengaruhi pertumbuhan dan perkembangan anak sesuai dengan rentang usia anak. Apabila kita dapat memberikan ruang kepada anak untuk bermain, maka secara tidak sadar kita pula telah mengurangi stres anak. Sehingga mengurangi resiko terjadinya masalah kesehatan dalam pertumbuhan dan perkembangan anak.

Permainan tradisional sangatlah populer sebelum masuknya teknologi ke Indonesia. Sebelumnnya, anak bermain dengan menggunakan alat sederhana dan seadanya. Tetapi saat ini, anak-anak sudah bermain dengan permainan yang berbasis teknologi seperti bermain gadget sehingga anak-anak mulai meninggalkan mainan tradisional. Permainan moderen tidak pula berdampak positif bagi anak, tetapi banyaknya dampak negatif yang bisa kita dapatkan, karena dengan bermain gadget anak hanya berfokus bermain sambil duduk saja dan hanya melatih kemampuan kognitif anak, tidak ada pergerakan otot-otot besar sehingga hal ini akan memperlambat perkembangan motorik anak, di samping terlambatnya perkembangan motorik anak, hal ini juga akan mempengaruhi kerusakan pada mata anak dalam penggunaan gadget.

Permainan tradisional merupakan permainan yang sederhana dan mudah di aplikasikan dalam kehidupan sehari-hari serta dalam permainan tradisional anak dapat mewarisi dan mencintai budaya daerah. Menurut Apriliawati dan Hartoto (2016) permaiman tradisional adalah suatu bentuk aktivitas yang dilakukan dengan sengaja tanpa ada unsur paksanaan yang sifatnya menyenangkan untuk meningkatkan potensi dalam diri setiap individu. Permainan tradisional pada dasarnya permainan yang dimainkan secara berkelompok, hal ini dapat memberikan ruang anak untuk bersosialisasi dengan lingkungan serta melatih dalam sifat demokratis anak. Disamping kedua hal tersebut tanpa kita sadari permainan tradisional dapat mengembangkan kemampuan motorik anak. Sesuai dengan penelitian yang telah dilakukan oleh Uswatun Hasanah (2016) tentang "Pengembangkan Kemampuan Fisik Motorik melalui Permainan Tradisional bagi Anak Usia Dini" mengemukakan permainan tradisional secara tidak langsung dapat memberikan kontribusi kepada anak-anak salah satunya yaitu pembentukan fisik yang sehat, bugar, tangguh, unggul dan berdaya saing. Salah satu permainan tradisional yang dapat mengembangkan kemampuan motorik anak yaitu permainan tengge-tengge/engklek. 
Efektifitas permainan tradisional tengge-tengge/engklek dalam penelitian ini juga didukung oleh beberapa perkembangan anak yang tidak diteliti tapi dimungkinkan dapat efektif pada permainan tradisional dalam perkembangan anak, yaitu bagi pengembangan sosial emosional, mengasah memori/kognitif, mengembangkan etika, serta meningkatkan kreativitas anak. Melalui bermain engklek dapat mengasah kemampuan anak untuk bersosialisasi dengan orang lain dan mengajarkan kebersamaan (Jamilah, 2017). Dalam bersosialisasi menghargai orang lain, dan belajar sikap demokratis. Mengasah memori otak dimana melalui bermain anak bisa mengembangkan kemampuan memori/kognitif yang ia miliki (Prastiwi, 2016). Dimana anak belajar berhitung dan menentukkan langkah-langkah yang akan ia lewati, serta mengenal benda-benda yang saat ia bermain, semakin anak bermain maka otaknya pun akan semakin terasah dan mendapatkan perkembangan memori yang jauh lebih baik.

Mengembangkan etika menurut Prastiwi (2016) anak mempelajari aturan, mempunyai tingkat sportivitas, dan tentu saja belajar bagaimana membangun etika yang benar. Dengan bermain, maka anak akan melakukan banyak hal bersama teman-temanya, anak tidak mudah curang dalam bermain karena berhadapan dengan aturan dunia permainan sebenarnya, hal ini akan melatih untuk dapat melakukan banyak hal dengan baik dan benar.

Jadi dari hasil dan teori di atas bahwasanya permainan tradisional tenggetengge merupakan salah satu permainan yang menjadi ciri khas dari bangsa, yang dapat digunakan sebagai stimulasi dalam melatih perkembangan motorik anak.

\section{KESIMPULAN}

Berdasarkan hasil penelitian maka dapat di simpulkan permainan tradisional efektif terhadap perkembangan motorik anak usia prasekolah di TK Aisyiyah Bustanul Atfal 1 dengan nilai $\mathrm{P}$ value $=0,000$ dimana lebih kecil dari $\alpha=0,05$. Sedangkan rekomendasi yang disarankan oleh peneliti adalah :

1. Institusi Sekolah. Hasil penelitian ini diharapkan menjadi masukan bagi lembaga pendidikan agar kiranya dapat digunakan salah satu alternatif untuk menunjang peningkatan kemampuan motorik agar siswa lebih termotivasi sekaligus mengenalkan budaya daerah melalui permainan-permainan yang ada di daerah Gorontalo.

2. Pendidikan. Dari hasil penelitian ini diharapkan dapat menambah wawasan lembaga pendidikan tentang permainan tradisional terhadap perkembangan motorik anak usia pra sekolah 4 sampai 5 tahun.

3. Kesehatan. Hasil penelitian ini diharapkan dapat menambah wawasan tentang permainan tradisional terhadap perkembangan motorik anak usia pra sekolah 4 sampai 5 tahun untuk dapat menjadi salah satu stimulasi memantau pertumbuhan dan perkembangan motorik anak sesuai dengan rentang usia. 
4. Bagi Peneliti. Dapat dijadikan referensi baru dalam mengembangkan penelitian selanjutnyaditambahakan pada salah satuvariebel seperti kognitif anak dan sosialisasi.

\section{DAFTAR PUSTAKA}

Apriliawati A.T., Hartoto S. 2016. Penerapan Permainan Tradisional dalam Pembelajaran Pendidikan Jasmani, Olahraga dan Kesehatan terhadap Kemampuan Motorik Siswa. Jurnal Pendidikan Olahraga dan Kesehatan, 04 (2), 522-528.

Depkes RI. 2012. Pedoman Pelaksanaan Stimulasi, Deteksi dan Intervensi Dini Tumbuh Kembang Anak ditingkat Pelayanan Dasar. Jakarta: Departemen Kesehatan Republik Indonesia, Direktorat Jendral Pembinaan Kesehatan Masyarakat Republik Indonesia

Depkes RI. 2014. Profil Kesehatan Indonesia Tahun 2013. Jakarta: Kementrian Kesehatan Republik Indonesia.

Desmita.2013.Psikologi Perkembangan Anak Usia Dini. Bandung : PT. Remaja Rosdakarya

Hasanah, U. 2016.Pengembangan Kemampuan Fisik Motorik melalui Permainan Tradisional.Jurnal Pendidikan Anak, 5 (1).717-733

Jamilah, R.J. Peran Permainan Tradisional Engklek dalam Peningkatan Motorik Kasar Anak Usia 5 sampai 6 Tahun di RA Al-Mukhlisin Medan TA.2016/2017.Universitas Islam Negeri Sumatra Utara. Skripsi

Kemenkes RI. 2013. Riset Kesehatan Dasar 2013. Jakarta:Kementrian Kesehatan Republik Indonesia

Perwitasari, A.C. 2016. Pengaruh Permainan Tradisional Engklek terhadap Perkembangan Motorik Kasar Anak Usia 5 sampai 6 tahun di TK Bhineka Karya Tunggulsari dan TK Islam Bakti VIII Wonorejo.Universitas Muhammadiyah Surakarta. Publikasi Ilmiah

Prastiwi, L. 2016. Pengaruh Model Pembelajaran Kooperatif Permainan Tradisional Engklek dan Gobak Sodor terhadap Kemampuan Motorik Kasar Anak TKIT Salsabila 5 Purworejo. Universitas Negeri Yogyakarta. SKRIPSI. 
Redaksi.2014.Sepuluh Permainan Tradisional Gorontalo ini Nyaris Punah. http://deGorontalo.co/sepuluh-permainan-tradisional-Gorontalo-ini-nyarispunah/. Diakses pada tanggal 4 Desember 2017.

Wulandari, D., Erawati, M. 2016. Buku Ajar Keperawatan Anak.Yogyakarta : Pustaka Pelajar 